\title{
Investigation on the Primary School District using Thiessen Polygon
}

\author{
SUN Xia ${ }^{1, a^{*}}, \mathrm{LI} \mathrm{ZaO}^{2, \mathrm{~b}}, \mathrm{LI} \mathrm{Jin}^{3, \mathrm{c}}$, YE Maosheng ${ }^{4, \mathrm{~d}}$, \\ ${ }^{1}$ Hefei University of Technology Danxia west road in hefei Anhui province ,China \\ ${ }^{2}$ Hefei University of Technology Danxia west road in hefei Anhui province ,China \\ ${ }^{3}$ Hefei University of Technology Danxia west road in hefei Anhui province ,China \\ ${ }^{4}$ Hefei University of Technology Danxia west road in hefei Anhui province ,China

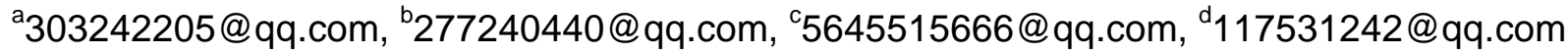

Keywords: school districts; primary school;Thiessen Polygons

Abstract. Nowadays, many problems have emerged in the district scope and service radius of urban elementary schools. Based on the present situation of elementary schools' layout in Hefei, this research used the Thiessen Polygons to generate new school district. The study found that the service radius of primary schools overlapped in the central part of urban area while this indicator was too large in the periphery of new district of urban area. This research pointed out the problems existed in urban elementary school district. Suggestions for the planning and service radius setting of elementary schools in urban areas were further put forward.

\section{Research Background and Methods}

At present, with gradually accelerated urban construction, especially construction of new towns, constant expansion of urban scale and renovation of old towns, population moves outward and rapidly increases in new towns and connected areas of new towns and old towns. Hence, the phenomenon of inconsistency between primary school layout, school district service scope and rapid urban development is getting prominent.

The definition of school district scope and building scale for China's primary and middle schools is usually in accordance with national standards, service radius and "one-thousand-person index" but the results usually cannot satisfy actual demands ${ }^{[1]}$. Therefore, SONG Xiaodong ${ }^{[2]}$, etc. explored city primary and middle school layout planning methods and proposed improvement methods. LIU Wei ${ }^{[3]}$, etc., based on GIS network analysis, initially divided service areas on the basis of travel distance, combined manual interpretation to clarify residential communities of each primary school, calculated building scale of primary schools, and focused on rational calculation with perpetual interpretation as the auxiliary means, thus enhancing scientific nature of regulatory plan indexes.

This paper, based on previous studies on the application of GPS technology in layout planning of city primary and middle schools, applies Thiessen polygon to generate the scope of primary school districts in different administrative regions of Hefei. Thiessen polygon is a continuous polygon composed of perpendicular bisector of lines connecting two primary school distribution points. The distance between any point within the polygon formed with such method and the primary school is the shortest so it can be used to analyze whether the current city primary school district division is reasonable or not; the distribution points, school district scope and service radius of city primary and middle schools directly affect pupils' action routes.

\section{Basic Data on Hefei Primary Schools}

According to the statistics of Hefei Planning Bureau and Education Bureau in 2011, the number of pupils in Hefei school districts was 205,200. There were 37 primary schools in Yaohai District, the main town area, 33 in Luyang District, 33 in Shushan District, 33 in Baohe District, 10 in Economic Technology Development Zone (Economic Development Zone for short hereinafter) and 10 in High-tech Technology Development Zone (High-tech Zone for short hereinafter), 158 in total.As is 
shown in Table 1. The number of primary schools in Economic Development Zone and High-tech Zone, two new towns, is small.

Tab 1 Statistics table for the numbers of primary schools in Hefei on the status quo

\begin{tabular}{c|c|c|c|c|c|c|c}
\hline District & $\begin{array}{l}\text { Yaohai } \\
\text { District }\end{array}$ & $\begin{array}{c}\text { Luyang } \\
\text { District }\end{array}$ & $\begin{array}{l}\text { Shushan } \\
\text { District }\end{array}$ & $\begin{array}{l}\text { Baohe } \\
\text { District }\end{array}$ & $\begin{array}{l}\text { Economic } \\
\text { Development Zone }\end{array}$ & $\begin{array}{l}\text { High-tech } \\
\text { Zone }\end{array}$ & total \\
\hline primary school & 32 & 32 & 25 & 28 & 10 & 10 & 137 \\
\hline nine-yearprimary & 5 & 1 & 8 & 7 & 0 & 0 & 21 \\
\hline school & 37 & 33 & 33 & 35 & 10 & 10 & 158 \\
\hline total & & 37 & &
\end{tabular}

\section{District Division of Hefei Primary School}

a-f in Fig. 1 respectively represent the school district division status of four main towns of Hefei including Baohe District, Shushan District, Luyang District and Yaohai District as well as two new towns of High-tech Zone and Economic Development Zone.

It can be noted from a-d that primary distribution points in four main towns are dense in areas close to the central town of Hefei and there are many service radius overlaps, which makes many regions far from belonging primary schools; some primary schools are located in the marginal positions of school district scopes. As a result, the walking distance of some pupils to the belonging school districts is longer than the walking distance to neighboring school districts. In places far away from main towns, primary school distribution points are extremely scare and the service radius is far greater than $500 \mathrm{~m}$ so the walking distance of pupils within school districts is greatly prolonged.

Hence, in future planning and resource allocation, some schools can be merged in places of main towns close to the central town where school distribution is dense. More schools should be added in places far away from the central town so as to reduce the school district scope and service radius of current schools.

$\mathrm{e}$ and $\mathrm{f}$ in Fig. 1 respectively indicate the school district division status of High-tech Zone and Economic Development Zone. High-tech Zone is the core western area according to Hefei's 141 urban development strategy. The number of primary schools was 9 in 2013. Economic Development Zone is located in Shushan District and now has 12 primary schools. Both High-tech Zone and Economic Development Zone are newly emerging towns of Hefei. It can seen from the figure that school distribution points in these two new towns are scare and the school district covers a very large area with the service radius being far more than $500 \mathrm{~m}$, thus causing inconvenience for pupils most of whom need to take public transportation such as bus.

Accordingly, in the new town planning and resource allocation process, the number of schools should be increased to reasonably control the school district scope and service radius of schools. 

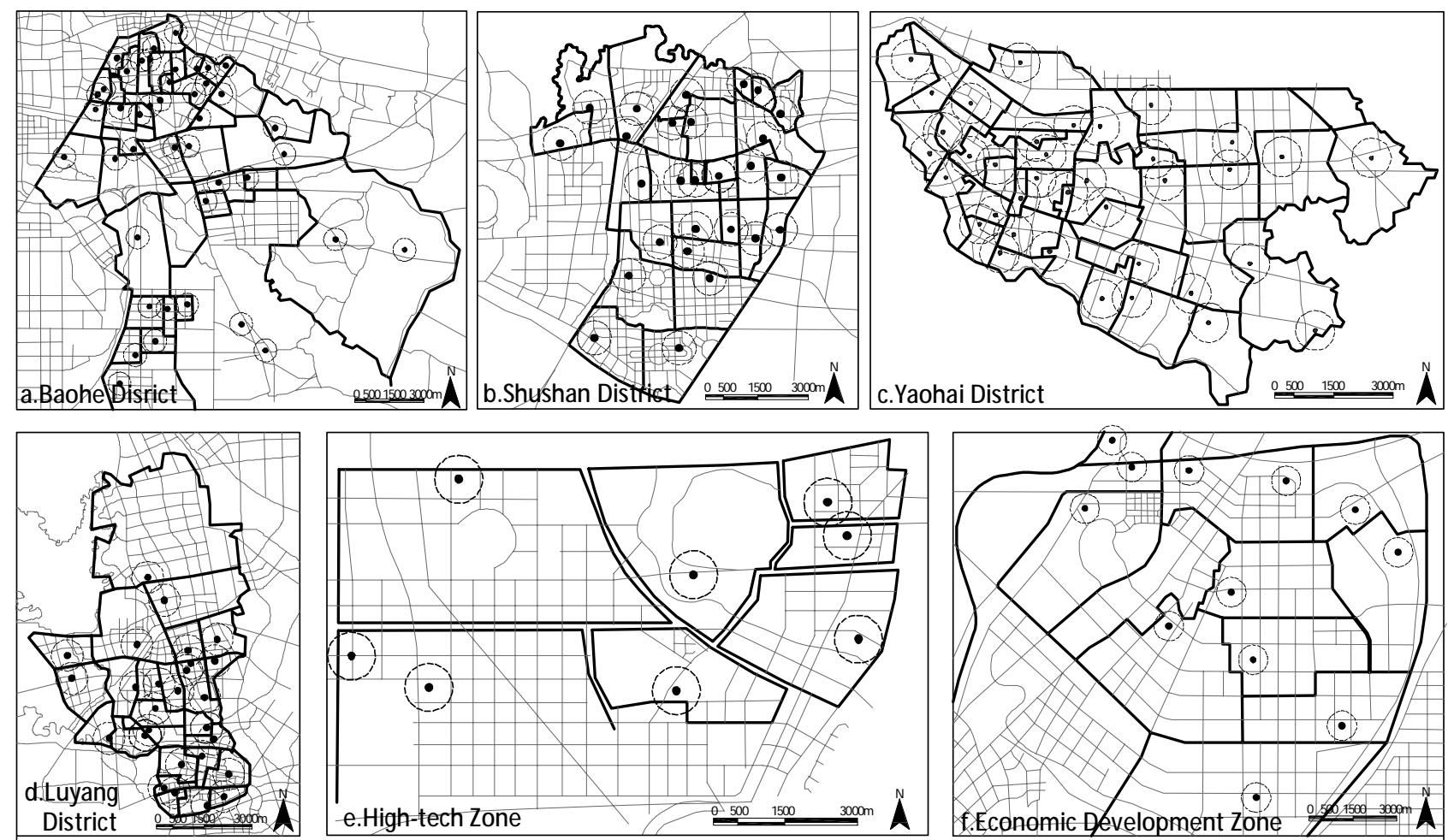

- the elementary school area

500 meters action circle

school service district

Fig 1 The school district division of Hefei

\section{Generated School District Division by Thiessen Polygon Method}

Thiessen polygon method is a common method used for division in GIS and its most important feature is "the distance between any point within the Thiessen polygon and the polygon belong point is the shortest". There's neither service zone overlap nor dead zone in Thiessen polygon. The shortcoming of the method is that it's located in urban margin, the service area is very large and the supply density is quite low. In terms of each space point goal, the distance from any space point of the Thiessen polygon is the shortest and the Thiessen polygon reflects its influencing scope to some extent. With its application in primary school service scope division, the distance between the residential point within the corresponding Thiessen polygon and the school is the shortest for each school ${ }^{[4]}$. Currently the division of primary and middle schools in Chinese cities is affected by management system and administrative segmentation so administrative region boundary is regarded as the basis for division of primary and middle school district division. Hence, it's more practical to apply Thiessen polygon in single administrative region school district division ${ }^{[2]}$.

Fig. 2 shows the primary school service scope division results of four central towns and two new towns in Hefei according to this method. It can be noted from the figure that the polygon area generated by places of four old towns close to the central town is relatively small. The closer the distance to the new towns, the larger the area and the polygon area generated by new towns is quite large. It means that some primary schools are relatively dense in the central town of Hefei. The closer to peripheral area of the city, the more scare the primary school distribution points. On the whole, the primary school distribution points are quite uneven. 

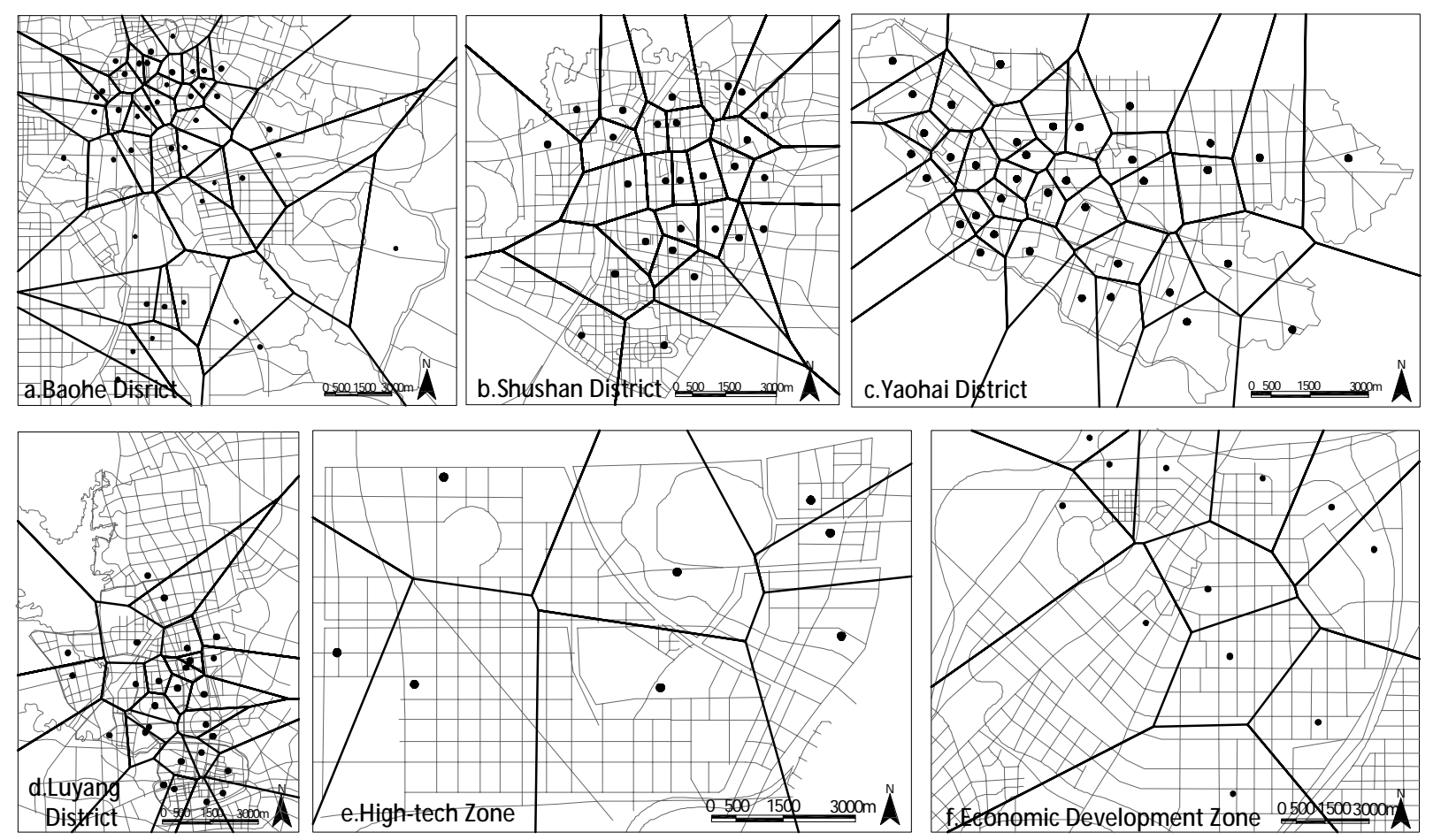

Fig 2 Thiessen polygon of primary schools in different area of Hefei

\section{Conclusion and Suggestions}

With Hefei city as an example, the study analyzes the primary school distribution points and school district scope of four old towns and two new towns of the city and finds that the problem of imbalance exists in the primary school distribution points and resource allocation of both new and old towns. The primary school distribution points are more dense in old towns while it's extremely scare in new towns. The service radius of some schools in the central old towns is small so there's overlap and the service radius of some schools in the periphery and new towns is too large.

Thiessen polygon method is used to regenerate the service scope of primary schools in different administrative regions. With this method, the distance between any point within the polygon generated and the belonging primary school is the shortest, thus providing technical and methodological support for the school district division of urban primary and middle schools in future.

Based on the analysis and survey results above, the author proposes the following suggestions on the setting of primary school distribution points and school district service radius for future:

(1) The resource allocation of primary schools in old and new towns should be conducted according to local conditions. The service radius of some schools in old towns is too small so overlap occurs. They can be merged to reduce the number of primary schools. The school district scope of some schools in new towns with mature development is too large and the number of schools can be gradually increased according to the increase in the right-age school entrance population. The newly emerging new towns is quite reasonable and standard in the pre-stage planning ratio so future planning and design development should take into account optimization of distribution points.

(3) When urban development is fast, changes take place in many aspects such as city roads and nature of land use, and changes in the population of old and new towns are also significant. Therefore, planning and design staff cannot completely apply normal standards for facility layout. The latest data should be obtained through field survey, and some new planning and design methods can be grasped to make the urban primary school layout and planning more reasonable.

\section{Acknowledgements}

National Natural Science Foundation of China (51208162) 


\section{References}

[1] LI Jin. GPS-Based Survey on Pupils' Routes After School and Study on Urban Space Optimization [D]. A thesis for Master's Degree of Hefei University of Technology. 2014 (4): 68-74.

[2] SONG Xiaodong, CHEN Chen, ZHOU Jing, ZHAI Yonglei, LI Shujie. Exploration and Improvement of Urban Primary and Middle School Layout Planning Methods [J]. Planning Method, 2014 (8), Volume 38, P48-56.

[3] LIU Wei, SUN Wei, XING Yan. Education Facility Service District Division and Scale Approval in Old Towns Based on GIS Network Analysis [J]. Planners, 2012 (1): 82-85.

[4] TONG Geng, LI Pengfei, LIU Zhiguo, HU Yijun. Study on Shenyang Primary and Middle School Layout Planning under GIS Technology Support [J]. Planners, 2014 (7): 68-74. 